\title{
Mental Health, Illness, Crunch, and Burnout: Discourses in Video Games Culture
}

\author{
Sky LaRell Anderson \\ University of St. Thomas \\ skyanderson@stthomas.edu
}

\author{
Stephanie Orme \\ Emmanuel College \\ ormes@emmanuel.edu
}

\begin{abstract}
This study investigates how video games culture addresses mental health and illness. Through a discourse analysis of eighty-three articles from four popular video games news websites, this paper describes the primary conceptions of mental health and illness as created in games culture. The study also targets how the news articles address the notions of burnout and crunch time in the games industry and how they relate to mental health and illness. The findings reveal seven thematic categories for how games journalism discourses address mental health and illness, with over half of the articles showcasing issues of game character portrayals. Only seven of the articles described burnout and crunch time as being related to issues of mental health and illness. An analysis of the findings suggests an overemphasis on both celebrating and critiquing video game portrayals of mental illness and an under-emphasis on advocacy and work-related issues in the games industry.
\end{abstract}

\section{Introduction}

This study investigates video games culture for how it addresses the topics of mental health and illness. Through a discourse analysis of eighty-three articles from four popular video games news websites, this paper describes the primary conceptions of mental health and illness as created in games culture. The study also targets how the news articles address the notions of burnout and crunch time in the games industry and how they relate to mental health and illness. The findings reveal seven thematic categories for how games journalism discourses address mental health and illness, with over half of the articles showcasing issues of game character portrayals. Only seven of the articles described burnout and crunch time as being related to issues of mental health and illness. An analysis of the findings suggests an overemphasis on both celebrating and critiquing video game portrayals of mental illness and an under-emphasis on advocacy and work-related issues in the games industry.
After a summary of salient literature, the paper provides a review of methodological considerations, and a report and analysis of the findings. This project takes a feed-forward approach to the subject matter, and the final section critiques current trends in games culture and advocates for specific future directions in both research and popular discourse.

\section{Mass media, video games, and depicting mental illness}

Mass media demonstrate a disappointing historical trend of portraying mental illness in harmful ways. News media often present mental illness as dangerous without publishing stories about treatment or recovery [1]. Meanwhile, narrative media tends to portray characters with mental illnesses as deviants or something to be feared. For instance, television characters with mental illnesses have been shown to be dramatically more violent compared to other characters [2]. Characters with mental illness in children's television are consistently portrayed as unadmirable while other characters label them as "mad," "losing your mind," or "crazy" [3]. Put simply, Wahl states that the "depictions of psychiatric disorders in children's media, moreover, appear to involve negative stereotypes similar to those in adult media" [3, p. 255]. However, there are some reasons to be hopeful: a longitudinal study found a significant improvement in news coverage of mental illness between 2005 and 2015 [4].

Game studies research has only barely begun to catalogue games' approach to portraying mental illness $[5,6]$. These portrayals often rely on tropes of hallucinations and PTSD [7, 8, 9]. Some work has targeted the-mostly debunked-relationship between games and addiction [10, 11]. Other work problematizes the pathologizing of video game play by providing nuance to discussions about high engagement of gameplay [12], game quitting behaviors [13], and diagnosis of gaming addiction [14, 15].

Other work has approached how games can benefit people with mental illnesses, such as to aid 
people with dementia [16], military veterans [17], and people who report traits associated with anxiety, insecurity, and depression [18]. For instance, Hoffman finds games that portray depression can improve empathy for people with depression, provide exposure to clinical discussions of depression, and increase opportunities for dialogue with friends and family [19]. Apart from portrayals, Stone finds that the act of game making can be a therapeutic practice [20].

Whether through the news, linear entertainment media, or video games, mass media depictions of mental illness can lead to real-world consequences inasmuch as they help form public opinion while leading to policy decisions that negatively affect people with mental illnesses [21]. Inaccurate depictions of mental illness also may reduce help-seeking behaviors, self-esteem, medication adherence, and recovery [22]. However, evidence suggests that improved discourses regarding mental health can increase the number of anti-stigmatizing news articles [23]. An examination into how games journalism addresses mental health demonstrates potential to improve discourses about these issues in video games, games culture, and the games industry. As Schomerus et al. demonstrate, beliefs about mental illness tend to improve with education regarding mental health [24].

\section{Burnout, crunch, and the video games industry}

Work-stress related disorders are increasing globally, primarily driven by emerging economic conditions that have placed overwhelming pressure on the labor force, both mentally and physically, such as increased work time per day [25]. Specifically, markets that rely on mental performance seem to invite mental health problems with few systems of recourse. As deVries and Wilkerson point out, the business industries "continue to isolate illness from the realms of work and life," [25, p. 45] and the underlying phenomenon remains undeniable: particular forms of work especially evident in the games industry contribute to mental health problems. These mental health challenges are not entirely dependent on work conditions - neighborhood and social support are more influential on mental health when compared to occupation or work conditions [26] - but when work becomes a factor in mental health, salient variables include physical and psychological demands, irregular schedules, and workplace harassment [27]. Psychological demands and irregular schedules seem particularly salient to the games industry and its relationship to crunch time, and even physical demands of work seem like a reasonable source of mental health stress given the exhaustion of working long hours over a series of weeks. While Marrone and Golowka claim that consequences of unemployment such as financial dependence and social isolation often greatly outweigh the mental health issues that come with working [28], evidence suggests that work-related factors may often contribute to depression and anxiety [29].

Burnout appears to be a catchall term in writing about the games industry regarding poor mental health due to professional or creative work. Ahola et al. describe burnout is a "state of exhaustion combined with doubts about the value of one's own work and competence" [30, p. 1023]. The term separates members of a creative industry from describing symptoms of mental illness, and instead it is a "psychologic construct" that can "be coded as a factor that influences health status" [30, p. 1023]. While variables such as supervisor behavior may negatively affect employee wellbeing [31], job strain tends to predict not only burnout but also depression. Ahola et al. point to high job strain as exacerbating both burnout and depression: "psychologic job demands and job control, and especially the combination of high demands and low control, called job strain, have predicted serious health consequences" [30, p. 1024]. Job strain, the result of the high demands of work combined with reduced agency to execute expected job performance, influences depression as well as burnout.

If burnout is the industry-friendly term for the result of job strain, then crunch time-often shortened to simply crunch-is the supposed cause. Legault and Ouellet describe the informally codified system of crunch time in the games industry, primarily by focusing on the expectation to work overtime and on weekends in the weeks leading up to a game's release [32]. Petrillo, Pimenta, Trindade, and Dietrich point to the fact that working "more than 12 hours a day is common, from 6 to 7 days per week, without rest intervals" [33, p. 709]. Crunch time infects employees with a constant feeling of stress trying to accomplish more than one can handle [34]. The extended hours at work are often uncompensated, and overtime work often bleeds into regularly expected work schedules outside of crunch time. Legault and Ouellet further describe how game development companies rely on an informal system of rewards and punishments that compel workers in the industry to comply to the unreasonable work expectations, primarily based on respect and prestige of working in the games industry [32]. Game companies construct their ideal worker as being "passionate about games" - with passion becoming a justification for continuing exploitative labor practices such as crunch [34]].

Crunch time has become a foregone conclusion in the games industry, and it is often blindly accepted as such [35]. Hamermesh and Lee point to time stress-a 
key feature of crunch time - as inherent in industries that rely on mental performance, such as the entertainment of games industries [36]. While widely practiced, crunch time is categorically detrimental to employees' wellbeing, especially in regards to mental health. Beaujot and Andersen find that crunch negatively impacts work-life balance [34], while Roxburgh suggests that perceived time pressure is associated with depression [36]. Crunch most egregiously affects workers in precarious employment, such as game testers who often do not have permanent job positions [38]. It has also been demonstrated to disproportionately affect women working in the games industry [34][39].

\section{Method}

Burnout and crunch appear to play a role in mental health and illness in games culture, yet the use of these terms appear to act as euphemisms that obfuscate poor working conditions that contribute to mental health issues. In other words, "crunch" may be an industryfriendly way to avoid addressing inhumane working conditions, and "burnout" may be a term used to avoid highlighting mental health issues. To exhume their role in gaming culture's relationship to mental health, and to holistically describe the nature of mental health and illness in gaming culture, this project examines the discourses regarding those subjects as they exist in gaming journalism. Games journalism encapsulates online writing on games and culture, and its role as a central hub for gaming's zeitgeist is undeniable. Games journalism's ability to both reflect and guide understanding on mental health in the larger cultural movement necessitates its study. This approach attempts to both describe the phenomenon as well as examine potential avenues for improving discourses regarding mental health. The study operationalizes games culture as it exists in popular English-language games journalism websites, although it acknowledges that this definition limits the scope of the study to particular regions of the world.

The guiding research questions for this project are as follows:

R1: What discourses exist in games culture regarding mental health and illness?

R2: How is workload, overwork, burnout, or crunch described in terms of mental health in games journalism?

The project uses discourse analysis as a method to describe how thought-leaders in games culture both emulate and dictate normalcy on the topic. Discourse analysis revolves around "an interest in properties of texts, the production, distribution, and consumption of texts," especially in terms of "the relationship of social practice to power relations, and hegemonic projects at the societal level" [40, p. 226]. In other words, this method is not simply a reflection or an analysis of discourse texts, but instead it also aims to describe how particular cultural constructs are created and reified.

For this study, the authors selected eighty-three articles from four of the most popular Englishlanguage games journalism websites for the study's corpus: IGN.com, PCGamer.com, Polygon.com, and Kotaku.com. The articles were selected by scoping keyword searches through a third-party search engine, meaning that the study did not utilize search engines hosted on the websites themselves. Articles were chosen that addressed subjects regarding mental health and illness through a web search for articles with the keywords "mental health" and "mental illness." Saturation of data appeared after approximately twenty articles per news website, except for IGN.com which yielded thirteen. The resulting corpus consisted of articles published between January 2013 and May 2021. The discourse analysis targeted the overarching subject matter of the articles. Data was coded according to the Grounded Theory Approach [41, 42, 43]. Following this method, theoretical categories were developed by drawing from the articles' subject matter followed by a comparison of categories, returning to the data, and then refining the categories. The goal of this method is to create a site-specific explanation of the data. The following two sections describe and analyze the findings.

\section{Findings}

The categorization method yielded seven categories. Each category demonstrated strong thematic consistency inasmuch as the articles fit one category each, except for two articles that fit two categories simultaneously. One article's subject matter did not fit any category: a story on suicide threats on the game streaming website Twitch.tv. The breakdown of the categories is as follows (table 1):

Table 1. Article categories

\begin{tabular}{|l|l|}
\hline Portraying Mental Illness & 30 articles \\
\hline Critiques of Mental Illness Portrayals & 14 articles \\
\hline Mental Health Activism & 10 articles \\
\hline $\begin{array}{l}\text { Gaming's Associations with Mental } \\
\text { Illness }\end{array}$ & 9 articles \\
\hline Burnout and Crunch & 8 articles \\
\hline Gaming Influencers and Mental Health & 6 articles \\
\hline Gaming to Aid Mental Health & 6 articles \\
\hline
\end{tabular}


The categories demonstrated a large disparity in which types of conversations are taking place in games journalism about mental health and illness: the mean of 11.86 articles per category does not adequately describe the disparity. However, the diversity in numbers can prove informative inasmuch as it highlights which conversations take precedence over others in gaming culture. The articles in each category were strongly similar to each other, leaving only a single article uncategorized. A full list of categorized articles can be found at https://pastebin.com/zqCJ67xv.

\subsection{Portraying mental illness}

Articles in the "Portraying Mental Illness" category showcased mental illness in games as a newsworthy topic in and of itself, meaning that the presence of this theme is rare or noteworthy enough to merit inclusion in the news site. The articles include feature stories on games such as Moons of Madness or Hellblade: Senua's Sacrifice. Some articles addressed production decisions, such as the article titled "Hellblade is an Audio Nightmare: Ninja Theory Uses Binaural Audio to Create a Horrifying Experience." Other articles described how the games came to be and how the theme of mental illness fits into the initial idea, like in the article "Interview: Infliction's Creator Talks Personal Horror and the Power of Kickstarter." Many of the articles featured interviews with game creators, tying the personal experiences of people with mental illness into the game production process. As a category, "Portraying Mental Illness" features articles that overwhelmingly praise these games for tackling the subject matter in innovative or pro-social ways.

\subsection{Critiques of mental illness portrayals}

Articles in the "Critiques of Mental Illness Portrayals" category offer a counterpoint to the praise often seen in the previous category. The articles levy critiques at games culture as a whole while featuring particular games as case studies. For instance, several articles critiqued how horror games rely on mental illness as a reductive plot device, such as in the articles "Nobody Wins When Horror Games Stigmatize Mental Illness" and "How the Asylum Jam Is Giving Horror a Much Needed Shock to the Heart." Other articles tackle individual games' approaches for portraying mental illness, such as relying on hurtful words and tropes, like in the articles "The Sims' Insane Trait Sucks" and "Gaming's Favorite Villain Is Mental Illness, and This Needs to Stop." The category reflects a cultural concern with moving beyond the history of harmful tropes in entertainment media regarding mental illness.

\subsection{Mental health activism}

"Mental Health Activism" includes articles that showcase mental health activism in games culture, such as at game festivals or other events. Several articles in this category describe how a mental health activism group participates in game conventions to raise awareness about issues of mental health: the articles "PAX Panel on Depression and Anxiety Discusses How They Created a Safe Haven" and "The AFK Room: More Than Just an Oasis Amid the Roar of QuakeCon" are examples. Other articles feature stories of how proceeds from game sales and other monies would be donated to mental health charities, such as the articles "All Hellblade Profits Go Toward Charity Today for World Mental Health Day" and "Devolver Digital Unveils New SNES Game With Profits Going to Charity." The remaining articles feature games as a form of activism, with articles introducing readers to games meant to help educate regarding issues of mental health.

\subsection{Gaming's association with mental illness}

Articles in the "Gaming's Associations with Mental Illness" category speak to conversations surrounding the relationship between gaming and mental illness. Several articles addressed how games organizations reacted to a World Health Organization classification of internet gaming disorder, as in the articles "ESA Sides with 'Internationally renowned' Mental Health Professionals to Oppose WHO's Gaming Disorder Proposal" and "Gaming Organizations React to World Health Organization's 'Gaming Disorder' Classification." Other articles described the common public discourse regarding games and violence, such as an article about a public official's statement that games contribute to mass shootings or another article on the history of blaming games for causing violence.

\subsection{Burnout and crunch}

Articles in the "Burnout and Crunch" category all introduce readers to issues of games production, work culture, and how the games industry is addressing - or ignoring - work-related issues that contribute to mental health concerns. Two of the seven articles in this category addressed how burnout exists as a mental health concern for Twitch streamers: “Twitch's New Creator Camp Will Help Streamers Cope with Burnout, Fan Challenges" and "Ninja's 12-hour Streaming Schedule Isn't What Mentally Exhausts Him." The remaining articles showcased industry conditions that cause significant mental health 
consequences for employees, such as the articles 'Devolver Digital Founder Says 'shameful' Developer Workload Is Industry's 'Dirty, Dirty Secret'" and "Report: Namco Ignored Programmer's Mental Health. Programmer Committed Suicide." It is important to note that more articles exist on burnout and crunch from these game news outlets; however, for this study, we were interested in articles that explicitly discussed mental health and illness. The disconnect between addressing crunch and burnout as problems relating to mental health, as evidenced in the low numbers of articles that make the connection, will be addressed in the following section.

\subsection{Remaining categories}

The remaining two categories included only seven articles total, and their topics are the least represented in games journalism as standalone discourses. However, the coherence of their subject matter merited their inclusion as standalone categories. The four articles in the category "Gaming Influencers and Mental Health" describe instances when prominent members of games culture, specifically gaming YouTubers and an e-sports star, faced mental health challenges, including the death of one influencer with mental illness. The final category, "Gaming to Aid Mental Health," includes six articles that address how games have been used as therapeutic interventions, including virtual reality games, the Dungeons and Dragons tabletop roleplaying game, and meditative arthouse games. Notably, three of the six articles were published in 2020, when there was a heightened attention to mental health concerns due to COVID-19 quarantines and social distancing.

\section{Analysis}

The nature of the Grounded Theory Approach, and one of its strengths, is the invited reflection that occurs through the re-analysis of the data and the ability to draw cursory conclusions based on the created categories [41, 42, 43]. An analysis of the categories reveals overall trends that provide insight into the state of games culture and its attitudes toward mental health and illness. First, analysis unearthed an undeniable meta-category of discourse: celebration, specifically meaning that three categories-namely "Portraying Mental Illness," "Mental Health Activism," and "Gaming to Aid Mental Health"-reveal a desire to celebrate the role of games as a boon to mental health. The categorical back-patting makes up approximately half of the articles in the corpus, precisely forty-six out of eighty-three articles. Whether these news outlets are showcasing games that portray mental illness in innovative ways or how gaming conventions can act as hosts for mental health activism, these articles, intentionally or not, position games culture as a forward-thinking safe haven of mental health discourse. While we do not dispute the facts of these articles, there may be a danger in overly-celebrating accomplishments when so much is left either unattended or unrecognized.

Second, and in spite of the overall tone of celebration found in games journalism, there remains significant concern and critique regarding the nature of mental health and illness in games culture. Twentythree articles presented challenges yet to be faced, or outright critiques, regarding mental health and illness. Specifically, the categories of "Critiques of Mental Illness Portrayals," "Burnout and Crunch," and "Gaming Influencers and Mental Health," point to how games are not the savior of mental health discourses in culture. Third, the lone category of "Gaming's Associations with Mental Illness," straddles the border between celebration and critique. The eight articles pointed to the many inaccuracies that other cultural thought leaders and news outlets perpetuate regarding mental illness and games, such as the demonstrably false relationship between violence and gameplay [44].

The most notable takeaway of this project-given that the second guiding research question asks for how games journalism describes workload, overwork, burnout, and crunch in terms of mental health-is that the analysis reveals how the articles did not adequately address burnout and crunch as variables that could contribute to mental health challenges. Of the eightythree articles in the study's corpus, a mere seven addressed issues of work and the games industry's issues regarding mental health. To be fair, these seven articles acknowledged the problems of particular workplace practices: they addressed crunch as being an unsustainable and an overall immoral work practice and burnout as being directly related to the nature of work expected by games industry employees, especially for those in the least secure positions. However, and anecdotally, the existence of many articles outside of this study's corpus that address burnout and crunch-all without addressing their problems as related to mental health-signifies the general disconnect between addressing burnout and crunch as mental health problems [30, 32, 34]. This disconnect contradicts the otherwise selfcongratulatory discourse surrounding mental health and illness. Games journalism, as an unofficial thought leader in games culture, can be a source of significant reading material for both game players and members of the games industry. To draw on Kenneth Burke, this journalism both reflects and selects the reality regarding mental health, illness, and games culture, but 
is also deflects reality in the form of over-emphasizing portrayals and underemphasizing the role of the documented problems in the games industry [45].

Somewhat related is the relatively small category of "Gaming Influencers and Mental Health." It reveals another aspect of games labor that often remains discounted, or marked distinct, from games production work, yet it demonstrates similar issues relating to mental health: overwork and the tragic consequences to mental health that may cause. The similarities are obvious upon reflection: gaming influencers are often insecurely employed and operate in a creative field much like many in the games industry who are most vulnerable to crunch time and burnout $[38,33,35]$. We address other implications regarding this relationship in the following and final section.

\section{Conclusions and feed-forward implications}

This project reveals a disparity in how games culture creates and ignores significant issues regarding mental health and illness. A preponderance of discourse showcases games' portrayals of mental illness-by both celebrating and critiquing those portrayals - while other discourses target advocacy for mental health and the relationship between games and mental illness. Issues of burnout and crunch are primarily ignored: the nature of the study required that the articles address "mental health" or "mental illness" in their texts, and by doing so the project highlights how few articles associate burnout and crunch with mental health. In other words, the fact that a mere eight articles - out of the eighty-three in the corpusdescribed even a cursory relationship between burnout and crunch to mental health challenges suggests that games culture does not often consider these workrelated issues to be relevant to conversations about mental illness. The primary meta-themes of the articles revolve around character portrayals and gameplay's associations with mental illness, and these discourses therefore obfuscate a real, and sometimes dangerous, problem facing the games industry.

While cataloguing discourses is critical to understanding popular conceptions of mental health and illness, it is here that we propose several implications of the analysis as well as possible future directions for both researchers and gaming thought leaders. As a caveat, the nature of the subject matter necessitates the abandonment of any pretend supposition of objectivity: instead, this project is feedforward and aims to advocate for improvement. First, burnout and crunch cannot continue to be treated as simply a workplace hazard and instead as a systematic issue leading to the harming of employees' mental health. While many writers are quick to point out the existence of crunch time and burnout in the games industry, these writers devote too little energy to acknowledging that these terms are often euphemisms for abusive employer behaviors leading to the degradation of employees' mental health. Put curtly, this will not do. Corporate-speak does not excuse the fact that the ramifications of burnout and crunch are not simply reduced productivity, but also the significant harm to the quality of life of employees at best and potential loss of life at worst. No game deadline is worth the continual abuse of employees' mental health.

Second, one of the smallest categories in the corpus points to a hidden subsection of the games industry and its potential challenges regarding mental health: game influencers or game content creators online. These individuals' careers consist of the online streaming of gameplay, shooting and editing gamerelated videos, and otherwise participating in the games industry in a field that did not exist even a mere fifteen years ago as of writing. However, these game content creators' jobs mimic several of the challenging characteristics of other creative professionals in the industry: insecure income, grueling deadlines, and the reliance on their mental well-being in order to perform the required creativity-based tasks. The articles in the study only hint at how these work conditions can contribute to poor mental health, but it is worth acknowledging that persons in the creative online content field, as a subsection of the games industry, are here to stay and are baked into the games industry for better or worse. Their jobs and mental health are not inconsequential simply because of their public presence, and future work on burnout, crunch, mental health, and gaming culture would do well not to ignore their existence.

Lastly, as a means of improving discourses in games culture regarding mental health and illness, the analysis suggests that visibility is key: visibility of portrayals of characters with mental illnesses, visibility of the unhealthy work conditions of creative professionals in the games industry, and visibility of the excellent work advocacy groups. Mental illness itself is still a taboo and misunderstood topic in many instances, and, given the real consequences to poor public understanding of mental health [1], this project aims to point to a more accurate understanding for how games culture constructs mental health through discourse.

\section{References}

[1] O.F. Wahl, "News Media Portrayal of Mental Illness: Implications for Public Policy," American Behavioral 
Scientist, 46(12), pp. 1594-1600, 2003. https://doi.org/10.1177/0002764203254615.

[2] D.L. Diefenbach, "The Portrayal of Mental Illness on Prime-Time Television," Journal of Community Psychology, 25(3), pp. 289-302, 1997. https://doi.org/10.1002/(SICI)15206629(199705)25:3<289::AID-JCOP5>3.0.CO;2-R.

[3] O.F. Wahl, "Depictions of Mental Illness in Children's Media," Journal of Mental Health, 12(3), pp. 249-258, 2003. https://doi.org/10.1080/0963823031000118230.

[4] R. Whitley and J. Wang, "Good news? A Longitudinal Analysis of Newspaper Portrayals of Mental Illness in Canada 2005 to 2015," The Canadian Journal of Psychiatry, 62(4), pp. 278-285, 2017. https://doi.org/10.1177/0706743716675856.

[5] S. L. Anderson, "Portraying mental illness in video games: Exploratory Case Studies in Mechanics, Interactivity, and Roleplay," Loading: The Journal of the Canadian Game Studies Association, 13(21), pp.2033, 2020. https://journals.sfu.ca/loading/index.php/ loading/article/view/277.

[6] J. Banks, R. Mejia, and A. Adams, Eds., 100 Greatest Video Game Characters, Roman \& Littlefield, Lanham, MD, 2017.

[7] N. Robinson, "Captain Martin Walker," 100 Greatest Video Game Characters, Jamie Banks, Robert Mejia, and Aubrie Adams (Eds.), pp. 31-32, Roman and Littlefield, Lanham, MD, 2017.

[8] J. Nay, "Isaac Clarke," 100 Greatest Video Game Characters, Jamie Banks, Robert Mejia, and Aubrie Adams (Eds.), pp. 82-84, Roman and Littlefield, Lanham, MD, 2017.

[9] C.J. Ferguson, "Alice," 100 Greatest Video Game Characters, Jamie Banks, Robert Mejia, and Aubrie Adams (Eds.), pp. 3-4, Roman and Littlefield, Lanham, MD, 2017.

[10] S. You, E. Kim, and D. Lee, "Virtually Real: Exploring Avatar Identification in Game Addiction Among Massively Multiplayer Online Role-Playing Games (MMORPG) Players," Games and Culture, 12(1), pp. 56-71, 2017. https://doi.org/10.1177/1555412015581087.

[11] S. Seok and B. DaCosta, "Problematic Mobile Gameplay Among the World's Most Intense Players: A Modern Pandemic or Casual Recreational Pursuit," Games and Culture, 13(4), pp. 385-405, 2018. https://doi.org/10.1177/1555412015616716.

[12] S. Seok and B. DaCosta, "Distinguishing Addiction from High Engagement: An Investigation into the Social Lives of Adolescent and Young Adult Massively Multiplayer Online Game Players," Games and Culture, 9(4), pp. 227-254, 2014. https://doi.org/10.1177/1555412014538811.

[13] K. Bergstrom, "Temporary Break or Permanent Departure? Rethinking What It Means to Quit EVE Online," Games and Culture, 14(3), pp. 276-296, 2019. https://doi.org/10.1177/1555412017698872.

[14] T. Bax, “'Internet Gaming Disorder' in China: Biomedical Sickness or Sociological Badness?" Games and Culture, 11(3), pp. 233-255, 2016. https://doi.org/10.1177/1555412014568188.
[15] A. Golub and K. Lingley, “'Just Like the Qing Empire’: Internet Addiction, MMOGs, and Moral Crisis in Contemporary China," Games and Culture, 3(1), pp. 5975, 2008. https://doi.org/10.1177/1555412007309526.

[16] C. Cutler, B. Hicks, and A. Innes, "Does Digital Gaming Enable Healthy Aging for Community-Dwelling People with Dementia?" Games and Culture, 11(1-2), pp. 104129, 2016. https://doi.org/10.1177/1555412015600580.

[17] J. Banks and J.G. Cole, "Diversion Drives and Superlative Soldiers: Gaming as Coping Practice among Military Personnel and Veterans," Game Studies 16(2), 2016. http://gamestudies.org/1602/articles/blankscole.

[18] T. Griebel, "Self-Portrayal in a Simulated Life: Projecting Personality and Values in the Sims 2," Game Studies, 6(1), 2006. http://gamestudies.org/0601/articles/griebel.

[19] K.M. Hoffman, "Social and Cognitive Affordances of Two Depression-Themed Games," Games and Culture, 14(7-8), 875-895, 2017. https://doi.org/10.1177/1555412017742307.

[20] K. Stone, "Time and Reparative Game Design: Queerness, Disability, and Affect," Game Studies, 18(3), 2018. http://gamestudies.org/1803/articles/stone.

[21] O.F. Wahl, Media Madness: Public Images of Mental Illness, Rutgers University Press, New Brunswick, NJ, 1995.

[22] H. Stuart, "Media Portrayal of Mental Illness and its Treatments: What Effect Does It Have on People with Mental Illness?" CNS Drugs, 20(2), pp. 99-106, 2006. https://doi.org/10.2165/00023210-200620020-00002.

[23] A. Thornicroft, R. Goulden, G. Shefer, D. Rhydderch, D. Rose, P. Williams, G. Thornicroft, and C. Henderson, "Newspaper Coverage of Mental Illness in England 2008-2011," British Journal of Psychiatry, 202, s64s69, 2013. https://doi.org/10.1192/bjp.bp.112.112920.

[24] G. Schomerus, C. Schwahn, A. Holzinger, P.W. Corrigan, H.J. Grabe, M.G. Carta, and M.C. Angermeyer, "Evolution of Public Attitudes about Mental Illness: A Systematic Review and MetaAnalysis," Acta Psychiatrica Scandinavica, 125, pp. 440-452, 2012. https://doi.org/ 10.1111/j.16000447.2012.01826.x.

[25] M.W. deVries and B. Wilkerson, "Stress, Work and Mental Health: A Global Perspective," Acta Neuropsychiatrica, 15(1), pp. 44-53, 2003. https://doi.org/10.1034/j.1601-5215.2003.00017.x.

[26] A. Marchand and M.E. Blanc, "The Contribution of Work and Non-work Factors to the Onset of Psychological Distress: An Eight-year Prospective Study of a Representative Sample of Employees in Canada," Journal of Occupational Health, 52(3), pp. 176-185, 2010. https://doi.org/10.1539/joh.L9140.

[27] A. Marchand, A. Demers, and P. Durand, "Does Work Really Cause Distress? The Contribution of Occupational Structure and Work Organization to the Experience of Psychological Distress," Social Science \& Medicine, 61(1), pp. 1-14, 2005. https://doi.org/10.1016/j.socscimed.2004.11.037.

[28] J. Marrone and E. Golowka, "If Work Makes People with Mental Illness Sick, What do Unemployment, Poverty, and Social Isolation Cause?" Speaking Out 
(Psychiatric Rehabilitation Journal), 23(2), pp. 187193, 1999. https://doi.org/10.1037/h0095171.

[29] M. Virtanen, S. Koskinen, M. Kivimäki, T. Honkonen, J. Vahtera, K. Ahola, and J. Lönnqvist, "Contribution of Non-Work and Work-Related Risk Factors to the Association Between Income and Mental Disorders in a Working Population: The Health 2000 Study," Occupational and Environmental Medicine, 65, pp. 171178, 2008. https://doi.org/10.1136/oem.2007.033159.

[30] K. Ahola, T. Honkonen, M. Kivimäki, M. Virtanen, E. Isometsä, A. Aromaa, and J. Lönnqvist, "Contribution of Burnout to the Association Between Job Strain and Depression: The Health 2000 Study," Journal of Occupational and Environmental Medicine, 48(10), pp. 1023-1030, 2006. https://doi.org/10.1097/01.jom.0000237437.84513.92.

[31] B. Gilbreath and P.G. Benson, "The Contribution of Supervisor Behaviour to Employee Psychological WellBeing," Stress, 18(3), 255-266, 2004. https://doi.org/10.1080/02678370412331317499.

[32] M.J. Legault and K. Ouellet, "So Into It They Forget What Time It Is? Video Game Designers and Unpaid Overtime," Enterprise Resource Planning: Concepts, Methodologies, Tools, and Applications, Information Resources Management Association, pp. 1232-1252, IGI Global, Hershey, PA, 2013.

[33] F. Petrillo, M. Pimenta, F. Trindade, and C. Dietrich, "Houston, We Have a Problem...: A Survey of Actual Problems in Computer Games Development," Proceedings of the 2008 ACM symposium on Applied computing, SAC'08, March 16-20, 2008, Fortaleza, Ceará, Brazil, pp. 707-711. https://doi.org/10.1145/1363686.1363854.

[34] M. Consalvo. "Crunched by Passion. Women Game Developers and Workplace Challenges," Beyond Barbie and Mortal Kombat: New Perspectives on Gender and Gaming, Yasmin B. Kafai, Carrie Heeter, Jill Denner, and Jennifer Y. Sun (Eds.), pp. 177-191, MIT Press, Cambridge, MA, 2008.

[35] R. Beaujot and R. Andersen, "Time-Crunch: The Impact of Time Spent in Paid and Unpaid Work, and Its
Division in Families," The Canadian Journal of Sociology, 32(3), pp. 295-315, 2007. https://doi.org/10.2307/20460645.

[36] D.S. Hamermesh and J. Lee, "Stressed Out on Four Continents: Time Crunch or Yuppie Kvetch?" The Review of Economics and Statistics, 89(2), pp. 374-383, 2007. https://doi.org/10.1162/rest.89.2.374.

[37] S. Roxburgh, “"There Just Aren't Enough Hours in the Day': The Mental Health Consequences of Time Pressure," Journal of Health and Social Behavior, 45(2), pp. 115-131, 2004. https://doi.org/10.1177/002214650404500201.

[38] E. Bulut, "Playboring in the Tester Pit: The Convergence of Precarity and the Degradation of Fun in Video Game Testing," Television \& New Media, 16(3), pp. 240-258, 2015. https://doi.org/10.1177/1527476414525241.

[39] J. Prescott and J. Bogg, "Segregation in a MaleDominated Industry: Women Working in the Computer Games Industry," International Journal of Gender, Science, and Technology, 3(1), 2011. http://genderandset.open.ac.uk/index.php/genderandset/ article/viewFile/122/259

[40] N. Fairclough, Discourse and Social Change, Polity Press, Malden, MA, 1992.

[41] B. Glaser and A. Strauss, The Discovery of Grounded Theory: Strategies for Qualitative Research, Aldine, Chicago, 1967.

[42] A. Strauss, Qualitative Analysis for Social Scientists, Cambridge University Press, New York, 1987.

[43] A. Strauss and J. Corbin, Basics of Qualitative Research: Grounded Theory Procedures and Techniques, Sage, Newbury Park, CA, 1990.

[44] A. Fishman, "Blame Game: Violent Video Games Do Not Cause Violence," Psychology Today, July 16, 2019. https://www.psychologytoday.com/us/blog/video-gamehealth/201907/blame-game-violent-video-games-donot-cause-violence.

[45] K. Burke, "Terministic Screens," Language as Symbolic Action, University of California Press, Berkley and Los Angeles, CA, pp. 44-62, 1966. 